\title{
Design of Robust Adaptive Observer against Measurement Noise for Sensorless Vector Control of Induction Motor Drives
}

\author{
Asma Boulmane $(\mathbb{D}$, Youssef Zidani $(\mathbb{D}$, Mohammed Chennani, and Driss Belkhayat
}

Faculty of Sciences and Technologies, Cadi Ayyad University, Marrakesh, Morocco

Correspondence should be addressed to Asma Boulmane; asma.boulmane@gmail.com

Received 30 March 2020; Revised 26 June 2020; Accepted 13 July 2020; Published 1 August 2020

Academic Editor: Luca Maresca

Copyright (c) 2020 Asma Boulmane et al. This is an open access article distributed under the Creative Commons Attribution License, which permits unrestricted use, distribution, and reproduction in any medium, provided the original work is properly cited.

\begin{abstract}
Position control in electrical drives is a challenging problem which is complicated by sensor noise and unknown disturbances. This paper proposes a new cascade sensorless speed control technique for induction motor drives suitable for electric vehicle applications using the full-order adaptive Luenberger observer that is insensitive to measurement noise and parametric variation. The adaptive speed law is obtained by the Lyapunov method using the estimated currents and fluxes. This technique ensures the stability of the induction motor considered as nonlinear dynamic system. Since the Luenberger observer works on deterministic environment, and it is most effective when sensor noise is limited, the present study aims to design a robust observer insensitive to measurement noise and parametric variation integrated in a cascade structure. The observer allows the filtering of the measured currents. To highlight the advantages of the new scheme, a comparative study and spectrum analysis will be presented. The proposed structure is verified using MATLAB/Simulink.
\end{abstract}

\section{Introduction}

Motor drive technology is a very complex and multidisciplinary field, and it has gone through a dynamic evolution over the last several decades by way of many inventions in power electronics (semiconductor devices, converters, and PWM techniques), electrical machines, and advanced control and simulation techniques.

Due to its robustness and rugged structure, the induction motor (IM) is widely used in industrial applications especially for electric and hybrid electric vehicles.

Control techniques of IMs can be divided into two main categories: scalar and vector controls. Scalar control is based on the steady-state model of the IM. Although this control is simple, easy to implement, and offers a good satisfactory steady-state response, this control is not suitable for applications requiring high dynamic performance. Vector (or field-oriented) control offers good satisfactory performance in terms of both steady-state and transient response. It allows separated control in a DC motor, which has drawbacks caused by the brushes $[1,2]$.
Vector control is based on having speed measurement. However, physical sensors have shortcomings that can degrade the control system. Indeed, sensor cost can substantially raise the total cost of a control system; sensors (and their associated wiring) reduce the reliability of the control system. Also, sensors can induce significant errors such as stochastic noise, cyclical errors, and limited responsiveness [3]. This has generated interest in sensorless control.

Sensorless control has received considerable attention during the last decades, both in research context and also in application domain on real processes. This technique ensures reduced hardware complexity, lower cost, reduced size of the drive machine, elimination of the sensor cables, better noise immunity, increased reliability, and lower maintenance requirements $[1,3,4]$.

There are a great variety of rotor speed estimation techniques in the literature. They can be classified into two main categories: (a) signal injection method and (b) stateobserver methods. The first category suffers from computational complexity and the requirement of external hardware for signal injection. Those in the second category are 
based on mathematical models of the IM and are simple and robust against disturbances [2]. These techniques include open-loop estimators, the Kalman filter, the Luenberger observer, and Model Reference Adaptive System [5, 6].

Authors of [7] combined MRAS and sliding mode for indirect vector control to improve the dynamic performance of the speed estimation, while authors of [8] designed a hybrid observer based on current sliding mode for low speed and flux linkage sliding mode for high speed and optimized using Adaptive Neural Fuzzy Interference System (ANFIS) and fuzzy PID. This system has advantages of robustness, and noise reduction is possible through the minimization of torque ripple and high precision of speed. The extended Kalman filter is tested in [9] under noisy current measurement for direct vector control.

The observer combines sensed signals with other knowledge of the control system to produce observed signals that are more accurate, less expensive to produce, and more reliable than sensed signals [3]. This observed state is used as a feedback signal in the control section.

Many techniques can be used to reduce noise sensitivity: reducing the observer bandwidth, filtering the observed disturbance, or modifying the observer compensator structure. As discussed in [10], lowering observer bandwidth will reduce noise susceptibility, but it also reduces the ability of the observer to improve the system. For example, reducing observer bandwidth reduces the accuracy of the observed disturbance signal.

In this paper, the adaptive full-order Luenberger observer is used to estimate stator currents and rotor fluxes. The observed states are then used to estimate the rotor speed based on the Lyapunov theory.

To reduce the noise measurements sensitivity of the Luenberger observer, a robust reduced-order observer is developed. It improves the response of the Luenberger observer in the presence of measurements noise.

Therefore, the paper is structured as follows: after the Introduction section, the mathematical dynamic model is described; then the Luenberger observer design and stability are detailed. The design of the reduced observer is shown followed by simulations results and conclusion.

\section{Mathematical Model and Control Technique of IM Drives}

2.1. Dynamic Model. The mathematical dynamic model of the IM consists of the differential equations describing the electromagnetic relationships of the stator and rotor as well as the equation of motion [1].

In this paper, the $\Gamma$-model is used. It consists of using only one leakage inductance $L_{L}$ instead of stator and rotor leakage inductances $L_{\mathrm{sl}}$ and $L_{r l}$ used in the T-model. The following equations describe the dynamic model of the IM:

$$
\left\{\begin{array}{l}
\frac{\mathrm{d} i_{s x}}{\mathrm{~d} t}=-\left(\frac{R_{s}\left(L_{M}+L_{L}\right)^{2}+R_{r} L_{M}^{2}}{L_{M} L_{L}\left(L_{M}+L_{L}\right)}\right) i_{s x}+\frac{R_{r}}{L_{L}\left(L_{M}+L_{L}\right)} \Phi_{r x}+\frac{p}{L_{L}} \omega \Phi_{r y}+\left(\frac{1}{L_{M}}+\frac{1}{L_{L}}\right) u_{s x} \\
\frac{\mathrm{d} i_{s y}}{\mathrm{~d} t}=-\left(\frac{R_{s}\left(L_{M}+L_{L}\right)^{2}+R_{r} L_{M}^{2}}{L_{M} L_{L}\left(L_{M}+L_{L}\right)}\right) i_{s y}-\frac{p}{L_{L}} \omega \Phi_{r x}+\frac{R_{r}}{L_{L}\left(L_{M}+L_{L}\right)} \Phi_{r y}+\left(\frac{1}{L_{M}}+\frac{1}{L_{L}}\right) u_{s y} \\
\frac{\mathrm{d} \Phi_{r x}}{\mathrm{~d} t}=\frac{R_{r} L_{M}}{L_{M}+L_{L}} i_{s x}-\frac{R_{r}}{L_{M}+L_{L}} \Phi_{r x}-p \omega \Phi_{r y} \\
\frac{\mathrm{d} \Phi_{r y}}{\mathrm{~d} t}=\frac{R_{r} L_{M}}{L_{M}+L_{L}} i_{s y}+p \omega \Phi_{r x}-\frac{R_{r}}{L_{M}+L_{L}} \Phi_{r y} \\
\frac{\mathrm{d} \omega}{\mathrm{d} t}=\frac{3}{2} \frac{p}{J}\left(\Phi_{s x} i_{s y}-\Phi_{s y} i_{s x}\right)-\frac{T_{L}}{J} .
\end{array}\right.
$$

\subsection{Vector Control. As mentioned before, the vector control} is based on imitating the DC motor behavior, which allows the separated control of the flux and the torque by adjusting, respectively, the direct and quadrature component of the stator current.

This technique is based on orientation of the dq-reference in such a way to eliminate the quadrature component. Thus, for the Rotor Field-Oriented Control (RFOC), the quadrature component of the flux is considered zero $\Phi_{r q}=0$, so the flux will be carried out entirely on the direct component $\Phi_{r}=\Phi_{r d}[11]$.
This control allows the determination of the stator voltages in the dq-reference frame, which attacks the threephase voltage source inverter (VSI) illustrated in Figure 1. It is composed of three arms, each has two complementary switches based on IGBT transistor. The control of these switches is ensured by different modulation techniques, of which the PWM is the simplest to implement. As shown in Figure 2, the switches' states are determined from the reference voltage and the high-frequency carrier [12]. Thus, Figure 3 presents the control structure. Indeed, the vector control allows the calculation of stator voltages, which are 


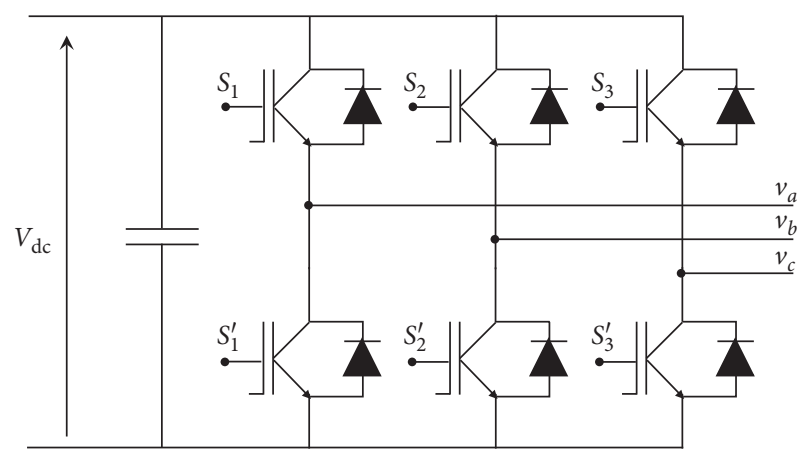

FIGURE 1: Voltage source inverter structure.

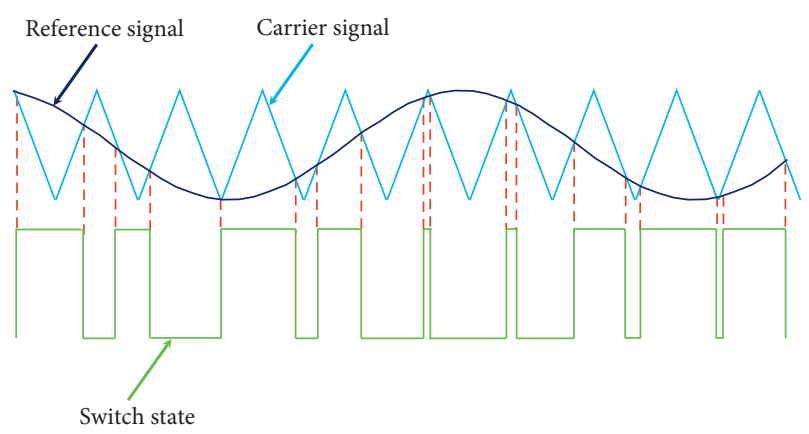

FIgUre 2: Pulse-width modulation principle.

used as reference voltages for the modulation technique. This allows the generation of the VSI switch states. And then, the inverter voltage output supplies the machine.

Different studies have analyzed the harmful impact of dead times on system performance. As known, this dead time is introduced to avoid the simultaneous conduction of two power devices (IGBT) in the same arm of the inverter. This solution causes system performance degradation (voltage output drop, disturbances and distortions of the signal, appearance of undesirable harmonic components, and reduction of the fundamental of the voltage). However, various dead time compensation methods are discussed in the literature. Some researches proposed different techniques to implement, without any changes at the hardware level; only the software part is slightly modified.

In some cases, as presented in [13], it is recommended to add an observer to the system to compensate the voltage magnitude, which has been affected due to dead times.

Authors of [14] propose a dead-time compensation method for a vector-controlled induction motor. This method includes the effect of dead time, turn-on/off time of switching devices, and voltage drops of switching devices and freewheeling diodes. It allows improvement of the system response and suppression of the current distortion in the motor. Then, the dead-time effect is eliminated.

Dead-time effects can be also greatly reduced using the proposed method in [15]. This method is tested for the sensorless vector control applications, and it has been verified that the speed error, under different dead time durations, can be reduced. Only slight modification of the controller software is required, and thus no additional hardware is needed in this method. They used a simple equation to calculate the real output voltage, and therefore the proposed method can effectively improve the controller performance without degrading its operating speed.

Moreover, it was verified in [16] that the compensation method improves the current waveform and improves the stability of the motor operation.

\section{Sensorless Vector Control Using Adaptive Observer}

3.1. The Full-Order Observer Luenberger Observer: Design and Stability. Based on the dynamic model of the induction motor, the full-order Luenberger observer is described by the following state presentation:

$$
\left\{\begin{array}{l}
\dot{\hat{x}}(t)=A \cdot \hat{x}(t)+B \cdot u(t)+L \cdot(y-\hat{y}) \\
\hat{y}(t)=C \cdot \hat{x}(t)
\end{array}\right.
$$

The state vector and the state matrix are $\hat{x}=\left(\begin{array}{ll}\hat{i}_{s} & \widehat{\Phi}_{r}\end{array}\right)^{T}$, $A=\left(\begin{array}{cc}a_{1} I & a_{2} I-a_{3} J \\ a_{4} I & -a_{5} I-a_{6} J\end{array}\right)$,

where $a_{1}=-\left(\left(R_{s}\left(L_{M}+L_{L}\right)^{2}+R_{r} L_{M}^{2}\right) / L_{M} L_{L}\left(L_{M}+L_{L}\right)\right)$; $a_{2}=-a_{5} / L_{L} ; a_{3}=-a_{6} / L_{L} ; a_{4}=-R_{r} a_{5} ; a_{5}=-\left(R_{r} / L_{M}+L_{L}\right)$; and $a_{6}=-p \omega$.

The input and output matrices are $B=\left(\begin{array}{cc}\left(1 / L_{M}\right)+\left(1 / L_{L}\right) & 0 \\ 0 & \left(1 / L_{M}\right)+\left(1 / L_{L}\right)\end{array}\right)^{T}, C=\left(\begin{array}{ll}1 & 0 \\ 0 & 1\end{array}\right)$.

The input and output vectors are $u=\left(\begin{array}{ll}u_{s x} & u_{s y}\end{array}\right)^{T}$, $y=\left(\begin{array}{cc}i_{s x} & i_{s y}\end{array}\right)^{T}$.

To determine the gain matrix $L$, the pole-placement method is used. This technique allows the determination of the observer dynamics. It consists in calculating the fullorder observer eigenvalues which are the characteristic polynomial roots. They are given by

$$
\begin{aligned}
\operatorname{det}\left(\lambda_{\mathrm{LO}} I(A-L C)\right)= & \left(\lambda_{\mathrm{LO}}^{2}+A_{\mathrm{LO}} \lambda_{\mathrm{LO}}+B_{\mathrm{LO}} \lambda_{\mathrm{LO}}\right) I \\
& +\left(C_{\mathrm{LO}} \lambda_{\mathrm{LO}}+D_{\mathrm{LO}}\right) J=0,
\end{aligned}
$$

where $\left\{\begin{array}{l}A_{\mathrm{LO}}=L_{1}-a_{1}-a_{5} \\ B_{\mathrm{LO}}=a_{5}\left(a_{1}-L_{1}\right)-a_{6} L_{2}+a_{2} L_{3}-a_{2} a_{4}+a_{3} L_{4} \\ C_{\mathrm{LO}}=a_{6}+L_{2} \\ D_{\mathrm{LO}}=a_{6} L_{1}-a_{1} a_{6}-a_{5} L_{2}+a_{2} L_{4}+a_{3} a_{4}-a_{3} L_{3}\end{array}\right.$.

In the same manner, the IM eigenvalues are given as follows:

$$
\operatorname{det}\left(\lambda_{\mathrm{IM}} I(A-L C)\right)=\left(\lambda_{\mathrm{IM}}^{2}+A_{\mathrm{IM}} \lambda_{\mathrm{IM}}+B_{\mathrm{IM}} \lambda_{\mathrm{IM}}\right) I
$$

where $\left\{\begin{array}{l}A_{\mathrm{IM}}=-a_{1}-a_{5}+\left(C_{\mathrm{IM}} \lambda_{\mathrm{IM}}+D_{\mathrm{IM}}\right) J=0, \\ B_{\mathrm{IM}}=a_{1} a_{5}-a_{2} a_{4} \\ C_{\mathrm{IM}}=a_{6} \\ D_{\mathrm{IM}}=-a_{1} a_{6}+a_{3} a_{4}\end{array}\right.$.

The poles of the observer and the motor must satisfy the equation $\lambda_{\mathrm{LO}}=K_{L} \lambda_{\mathrm{IM}}$, where $K_{L}>1$ [17]. Thus, the identification of both characteristic polynomials (3) and $K_{L} *(4)$ leads to the following results: 


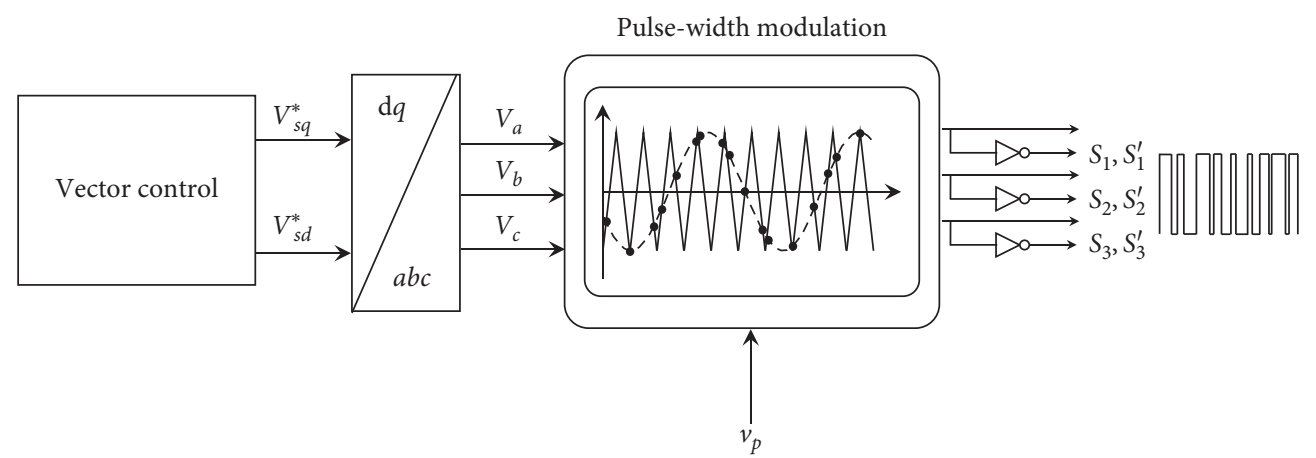

Figure 3: Induction machine control.

$$
\left\{\begin{array}{l}
L_{1}=\left(K_{L}-1\right)\left(-a_{1}-a_{5}\right), \\
L_{2}=\left(K_{L}-1\right) a_{6}, \\
L_{3}=-\left(K_{L}-1\right) R_{r} \frac{a_{6}^{2}-a_{5}^{2}}{a_{6}^{2}+a_{5}^{2}}, \\
L_{4}=-\left(K_{L}-1\right) p L_{L} \omega .
\end{array}\right.
$$

The poles of the observer are chosen to accelerate its convergence. But they must stay slow in comparison to the measurement noise, so the constant $K_{L}$ is usually set small.

3.2. Rotor Speed Estimation. To determine the rotor speed adaptive mechanism, the Lyapunov theorem is used. This technique is suitable for determining the stability of nonlinear dynamic systems such as IM drives. The main idea is to introduce a generalized energy function called the Lyapunov function, which is zero at the equilibrium and positive elsewhere. The equilibrium will be stable if we can show that the Lyapunov function decreases along the trajectories of the system [18]. Thus, the Lyapunov function is defined as follows [17]:

$$
V_{\omega}=e^{T} e+\frac{\Delta \omega^{2}}{\lambda_{\omega}}
$$

where $e=X-\widehat{X}$ is the estimation error.

Its derivative is defined as $\dot{e}=\widehat{A} \cdot e+\Delta A \cdot \widehat{X}$, and $\Delta A=A(\omega)-A(\widehat{\omega})=\left(\begin{array}{cc}0 & \left(p / L_{L}\right) \Delta \omega J \\ 0 & p \Delta \omega J\end{array}\right)$.

Therefore, the derivative of $V_{\omega}$ is given by

$$
\begin{aligned}
\frac{\mathrm{d} V_{\omega}}{\mathrm{d} t}= & e^{T}\left(\widehat{A}^{T}+\widehat{A}\right) e-2 \frac{p}{L_{L}}\left(\widehat{\Phi}_{r \beta} e_{I_{s \alpha}}-\widehat{\Phi}_{r \alpha} e_{I_{s \beta}}\right) \Delta \omega \\
& -2 \frac{\Delta \omega}{\lambda_{\omega}} \frac{\mathrm{d} \widehat{\omega}}{\mathrm{d} t}+\varepsilon_{\omega},
\end{aligned}
$$

where $\varepsilon_{\omega}=2 p\left(\widehat{\Phi}_{r \alpha} e_{\Phi_{r \beta}}-\widehat{\Phi}_{r \beta} e_{\Phi_{r \alpha}}\right) \Delta \omega$.

Then, the adaptive law is obtained as

$$
\widehat{\omega}=K_{p}\left(\widehat{\Phi}_{r \beta} e_{I_{s \alpha}}-\widehat{\Phi}_{r \alpha} e_{I_{s \beta}}\right)+K_{i} \int\left(\widehat{\Phi}_{r \beta} e_{I_{s \alpha}}-\widehat{\Phi}_{r \alpha} e_{I_{s \beta}}\right) \text {. }
$$

3.3. Noise in the Luenberger Observer. The Luenberger observers are most effective when the sensor produces limited noise. Indeed, they often can exacerbate sensor noise, which is frequently a problem in motion control systems. This noise comes from two major sources: electromagnetic interference (EMI) generated by power converters that is then transmitted to the control section and resolution limitations in sensors. EMI can be reduced through appropriate wiring practices and through the selection of components that limit noise generation, whereas resolution noise from sensors is more difficult to address $[19,20]$.

In this study, the position sensor is not used. However, the noise could be transmitted via the observer. In fact, the speed estimation is based on the current measurements. Figure 4 shows the structure of the designed observer in the presence of the measurements noise. To improve the system performance, a reduced-order observer is designed.

3.4. Design of the Reduced-Order Observer. The reducedorder observer aims to filter the measured currents before reaching the Luenberger observer as can be explained in Figure 5 .

The actual reduced observer tracks only a subset of the state vector contrary to the first observer referred to as an identity observer as it tracks the entire state vector. It takes the following form [21]:

$$
\left\{\begin{array}{l}
\dot{\hat{x}}_{e}(t)=A_{e} \cdot \widehat{x}_{e}(t)+B_{e} \cdot u(t)+K \cdot(y-\hat{y}), \\
\hat{y}(t)=C_{e} \cdot \hat{x}_{e}(t)
\end{array}\right.
$$

where the state vector is given by $\widehat{x}_{e}=\left(\begin{array}{c}\widehat{\Phi}_{s} \\ \widehat{\Phi}_{r}\end{array}\right)=\left(\begin{array}{c}\widehat{\Phi}_{s x}+j \widehat{\Phi}_{s y} \\ \widehat{\Phi}_{r x}+j \widehat{\Phi}_{r y}\end{array}\right)$.

$$
\text { And the state matrix is }
$$$$
A_{e}=\left(\begin{array}{cc}
-R_{s e}\left(\left(1 / L_{M e}\right)+\left(1 / L_{L e}\right)\right) & R_{s e} / L_{L e} \\
R_{r e} / L_{L e} & -\left(R_{r e} / L_{L e}\right)+j p \omega
\end{array}\right) .
$$

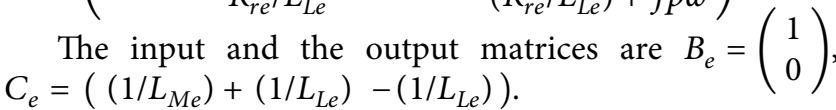

The observer gain matrix is

$K=R_{e} \cdot k=\left(\begin{array}{cc}R_{s e} & 0 \\ 0 & R_{r e}\end{array}\right)\left(\begin{array}{l}k_{s x}+j k_{s y} \\ k_{r x}+j k_{r y}\end{array}\right)$. 


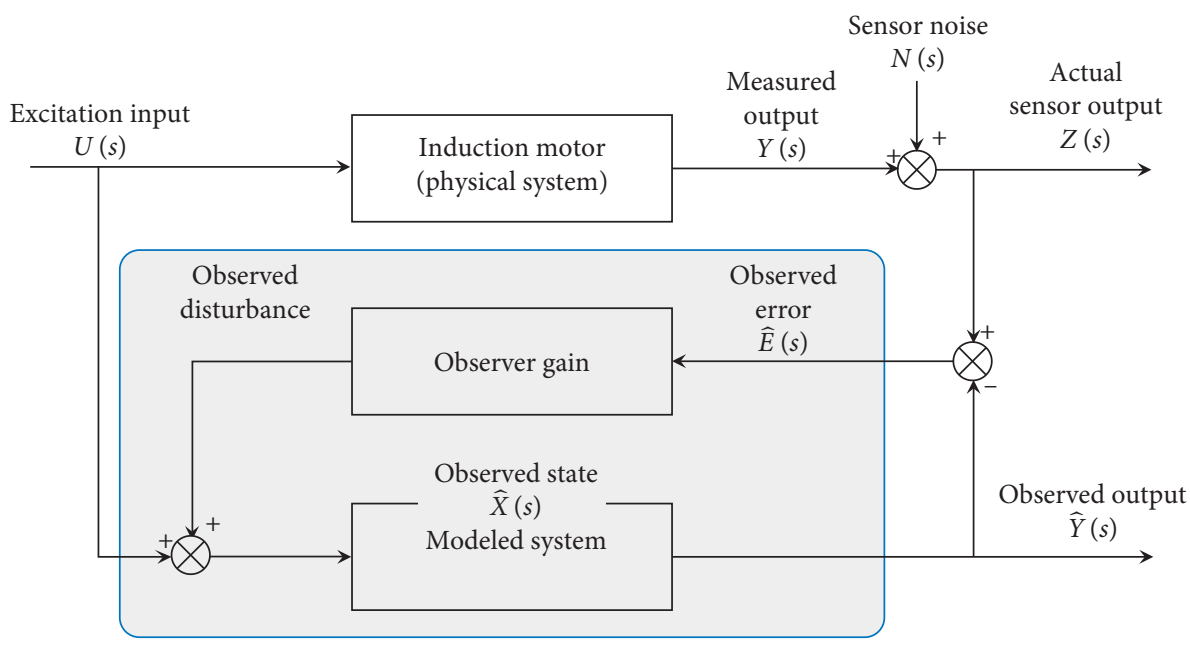

Figure 4: Structure of the full-order Luenberger observer in the presence of sensor noise.

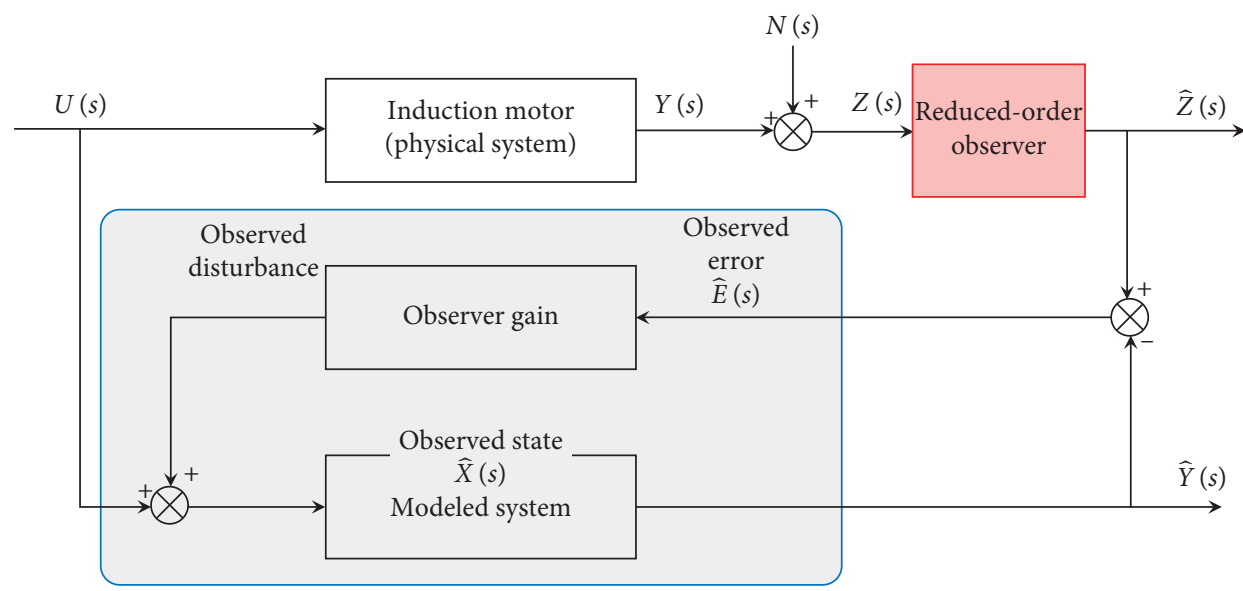

Figure 5: Proposed structure using the reduced-order observer.

The estimated fluxes are

$\left\{\mathrm{d} \widehat{\Phi}_{s} / \mathrm{d} t=u_{s}-R_{s e}\left(\left(1+k_{s}\right) \widehat{i}_{s}-k_{s} i_{s}\right)\right.$.

$\mathrm{d} \widehat{\Phi}_{r} / \mathrm{d} t=j p \omega \widehat{\Phi}_{r}-R_{r e} \widehat{i}_{r}$

The estimated

currents

$\left\{\widehat{i}_{s}=\left(\widehat{\Phi}_{s} / L_{M e}\right)-\left(\widehat{\Phi}_{r}-\widehat{\Phi}_{s} / L_{L e}\right)\right.$.

$\left\{\hat{i}_{r}=k_{r}\left(\hat{i}_{s}-i_{s}\right)+\left(\widehat{\Phi}_{r}-\widehat{\Phi}_{s} / L_{L e}\right) \cdot\right.$

As the observer poles are the eigenvalues of the matrix $\left(A_{e}-R_{e} k C_{e}\right)$, then the characteristic polynomial of the observer is given by

$$
P(s)=s^{2}+c_{1} s+c_{2}=s^{2}-\left(p_{1}+p_{2}\right) s+p_{1} p_{2},
$$

are where $p_{1}$ and $p_{2}$ are the characteristic polynomial roots.

The determination of the gain matrix $k$ in the observer is the same mathematical problem as the problem of determining the feedback matrix in the pole-placement problem. The selection of the observer poles is a compromise between sensitivity to measurement errors and rapid recovery of initial errors. A fast observer will converge quickly, but it will also be sensitive to measurement errors. The resolution is based on Ackermann's formula $k=R_{e}^{-1} P\left(A_{e}\right) \Theta^{-1}\left[\begin{array}{l}0 \\ 1\end{array}\right][18$, 21]:

$$
k=\left(\begin{array}{cc}
\frac{1}{R_{s e}} & 0 \\
0 & \frac{1}{R_{r e}}
\end{array}\right)\left(A_{e}^{2}+c_{1} A_{e}+c_{2} I\right)\left(\begin{array}{c}
\frac{L_{M e} L_{L e}\left(R_{r e}+j p \omega\left(L_{M e}+L_{L e}\right)\right)}{R_{r e}^{2}+p^{2} \omega^{2}\left(L_{M e}+L_{L e}\right)^{2}} \\
\frac{\left(L_{L e}^{2}+L_{M e} L_{L e}\right)\left(R_{r e}+j p \omega\left(L_{M e}+L_{L e}\right)\right)}{R_{r e}^{2}+p^{2} \omega^{2}\left(L_{M e}+L_{L e}\right)^{2}}
\end{array}\right),
$$


where $\Theta=\left(\begin{array}{c}C_{e} \\ C_{e} A_{e}\end{array}\right)$ is the observability matrix of system (9). This matrix is invertible when the system is observable. Then, the gain matrix is given by

$$
k=\left(\begin{array}{c}
\frac{c_{2}\left(L_{M e} L_{L e} / R_{s e}\right)\left(R_{r e}+j p \omega\left(L_{M e}+L_{L e}\right)\right)}{R_{r e}^{2}+p^{2} \omega^{2}\left(L_{M e}+L_{L e}\right)^{2}}-1 \\
\frac{\left(L_{L e}\left(\left(L_{M e}+L_{L e}\right) / R_{r e}\right)\right)\left(R_{r e}+j p \omega\left(L_{M e}+L_{L e}\right)\right)}{R_{r e}^{2}+p^{2} \omega^{2}\left(L_{M e}+L_{L e}\right)^{2}}+1-\left(c_{1}+j p \omega\right)
\end{array}\right) .
$$

Components of the gain matrix are obtained by identification as follows:

$$
\left\{\begin{array}{l}
k_{s x}=\frac{\left(\left(L_{M e} L_{L e}\right) / R_{s e}\right)\left(\Re\left(c_{2}\right) R_{r e}-\mathfrak{J}\left(c_{2}\right) p \omega\left(L_{M e}+L_{L e}\right)\right)}{R_{r e}^{2}+p^{2} \omega^{2}\left(L_{M e}+L_{L e}\right)^{2}}-1, \\
k_{s y}=\frac{\left(L_{M e} L_{L e} / R_{s e}\right)\left(\mathfrak{I}\left(c_{2}\right) R_{r e}+\mathfrak{R}\left(c_{2}\right) p \omega\left(L_{M e}+L_{L e}\right)\right)}{R_{r e}^{2}+p^{2} \omega^{2}\left(L_{M e}+L_{L e}\right)^{2}}-1, \\
k_{r x}=\frac{\left(L_{L e}\left(\left(L_{M e}+L_{L e}\right) / R_{r e}\right)\right)\left(\mathfrak{R}\left(c_{2}\right) R_{r e}-\mathfrak{I}\left(c_{2}\right) p \omega\left(L_{M e}+L_{L e}\right)\right)}{R_{r e}^{2}+p^{2} \omega^{2}\left(L_{M e}+L_{L e}\right)^{2}}+1-\frac{L_{L e}}{R_{r e}} \mathfrak{I}\left(c_{1}\right), \\
k_{r y}=\frac{\left(L_{L e}\left(\left(L_{M e}+L_{L e}\right) / R_{r e}\right)\right)\left(\mathfrak{I}\left(c_{2}\right) R_{r e}+\mathfrak{R}\left(c_{2}\right) p \omega\left(L_{M e}+L_{L e}\right)\right)}{R_{r e}^{2}+p^{2} \omega^{2}\left(L_{M e}+L_{L e}\right)^{2}}-\frac{L_{L e}}{R_{r e}}\left(\mathfrak{I}\left(c_{1}\right) p \omega\right) .
\end{array}\right.
$$

To summarize, the actual study combines the full-order Luenberger observer and the reduced-order observer to accurize the response system. The proposed structure allows a noise immunity, and it is insensitive to parametric variations. Figure 6 describes the bloc diagram used to verify the proposed structure.

\section{Simulation Results}

The proposed structure is verified using MATLAB/Simulink. The induction motor parameters are shown in Table 1.

The following simulations are carried out under a parametric variation of the stator resistance $(+20 \%$ of the rated value). The rated load torque is applied at $3 \mathrm{~s}$ and removed at $7 \mathrm{~s}$. The speed is kept constant at $600 \mathrm{rpm}$.

By integrating measurement noise, increasing the stator resistance, and applying the load torque, the system response is influenced. In fact, speed oscillations around the final value appear smaller when the reduced-order observer is used (Figure $7(\mathrm{a})$ ). This leads to an error that exceeds $75 \%$ when only the Luenberger observer is used. The integration of the filter reduces this error to $20 \%$ (Figure $7(\mathrm{~b})$ ). The electromagnetic torque (Figure $7(\mathrm{c})$ ) and $q$-axis stator current (Figure $7(\mathrm{~d})$ ) are affected too, especially when the rated load torque is applied.

Even though the stator resistance is increased, the reduced-order observer maintains the flux orientation (Figures 8(a) and 8(b)), and the error is negligible contrary to the use of Luenberger observer only where the error reaches $25 \%$ (Figure $8(\mathrm{~d})$ ).

The reduced-order observer allows $\alpha$-axis rotor flux (Figure 9(a)) and the stator currents (Figure 9(b)) to keep their sinusoidal forms despite the disturbances caused by the noise measurements, while the Luenberger observer alone does not manage to reject these disturbances, which distort signals.

Spectrum analysis shows how the reduced-order observer decreases THD and increases the fundamental amplitude for both current (Figures 10 and 11) and torque (Figures 12 and 13). 


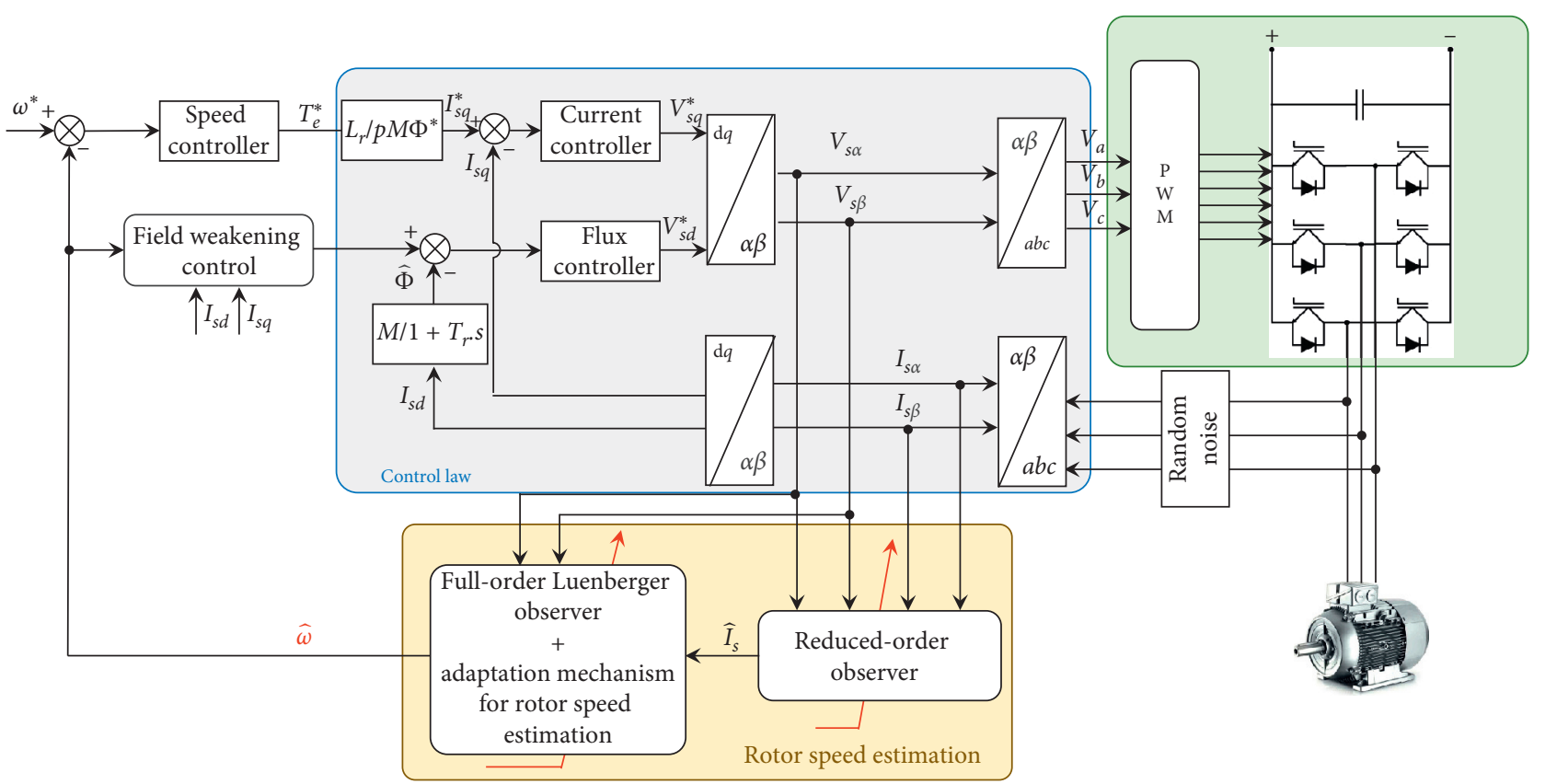

FIGURE 6: Sensorless vector control using a cascade structure of the full-order Luenberger and the reduced-order observers.

TABLE 1: Induction motor parameters.

\begin{tabular}{|c|c|c|c|c|c|c|}
\hline \multicolumn{3}{|c|}{ T-model } & \multicolumn{3}{|c|}{$\Gamma$-model } & Units \\
\hline Stator resistance & $R_{s}^{T}$ & 6.8 & Stator resistance & $R_{s}$ & 6.8 & $\Omega$ \\
\hline Rotor resistance & $R_{r}^{T}$ & 5.43 & Rotor resistance & $R_{r}^{s}$ & 6.77 & $\Omega$ \\
\hline Stator inductances & $L_{s}^{T}=\stackrel{r}{M}+L_{s l}$ & 0.3973 & Magnetizing inductance & $L_{M}^{r}$ & 0.3973 & $\mathrm{H}$ \\
\hline Rotor inductances & $L_{r}^{T}=M+L_{r l}$ & 0.3558 & Leakage inductance & $L_{L}$ & 0.0463 & $\mathrm{H}$ \\
\hline Mutual inductance & $M$ & 0.3558 & \multirow{4}{*}{\multicolumn{3}{|c|}{$\begin{array}{c}R_{s}=R_{s}^{T} ; R_{r}=R_{r}^{T} / k_{\gamma}^{2} ; L_{M}=M / k_{\gamma} ; \\
L_{L}=\left(L_{s l} / k_{\gamma}\right)+\left(L_{r l} / k_{\gamma}^{2}\right) ; k_{\gamma}=M /\left(M+L_{s l}\right)\end{array}$}} & $\mathrm{H}$ \\
\hline Total inertia & $J$ & $2.10^{-2}$ & & & & $\mathrm{~kg} \cdot \mathrm{m}^{2}$ \\
\hline Friction coefficient & $F$ & $2,5.10^{-4}$ & & & & Nm.s.rad ${ }^{-1}$ \\
\hline Pole pairs number & $P$ & 2 & & & & \\
\hline
\end{tabular}

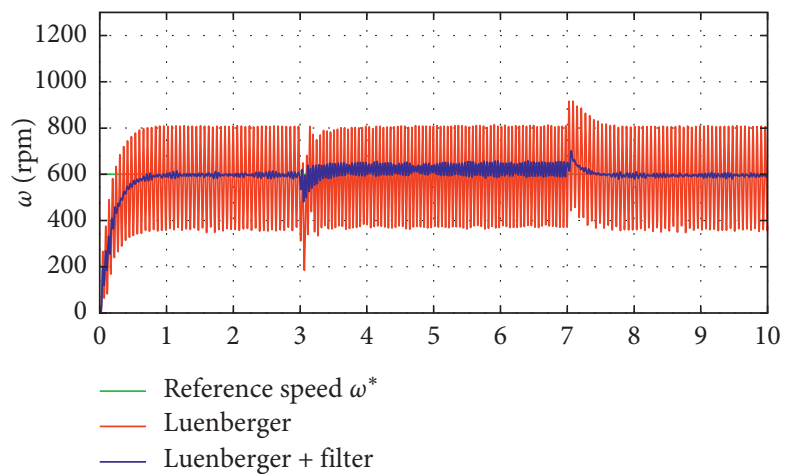

(a)

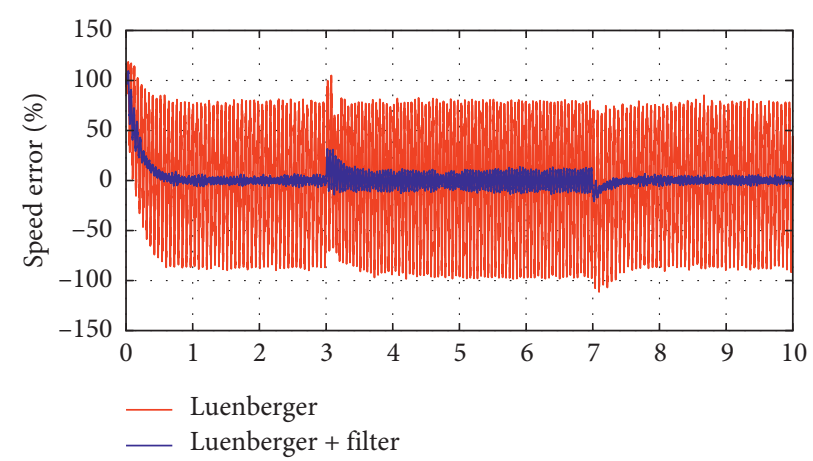

(b)

FIgURE 7: Continued. 


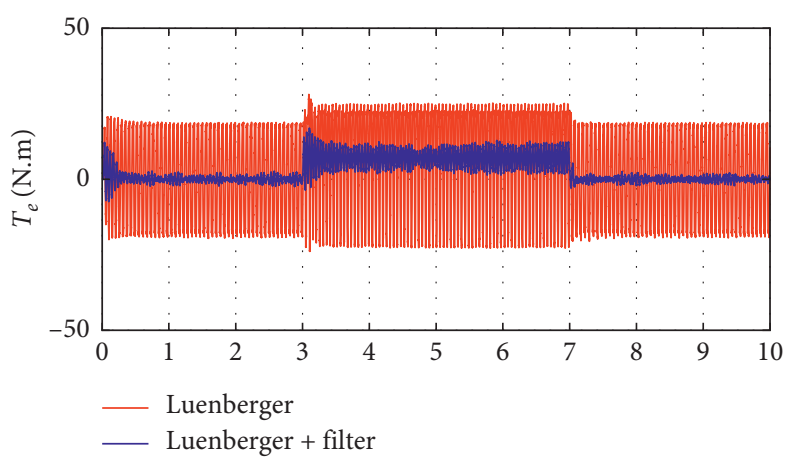

(c)

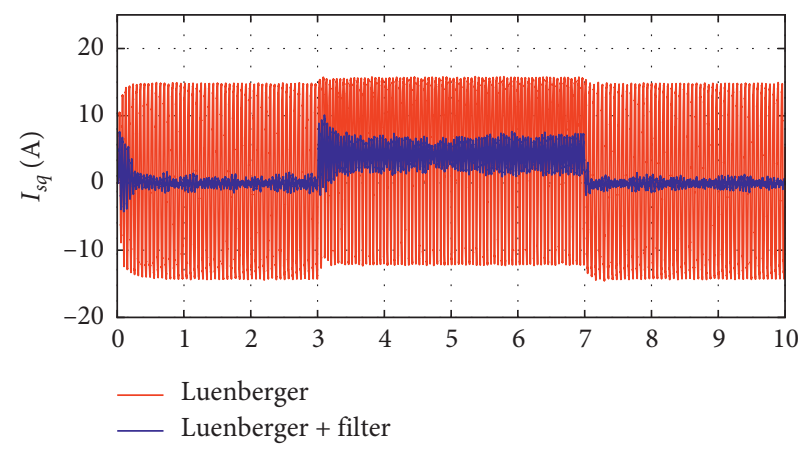

(d)

Figure 7: (a) Rotor speed. (b) Speed error. (c) Electromagnetic torque. (d) q-axis stator current.

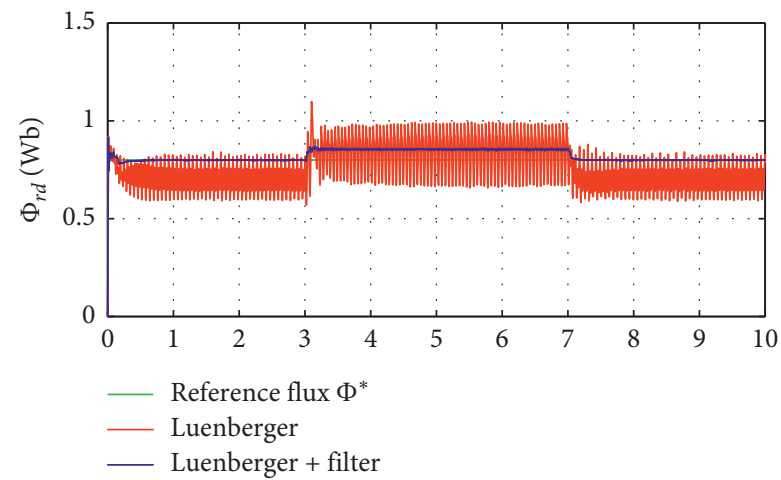

(a)

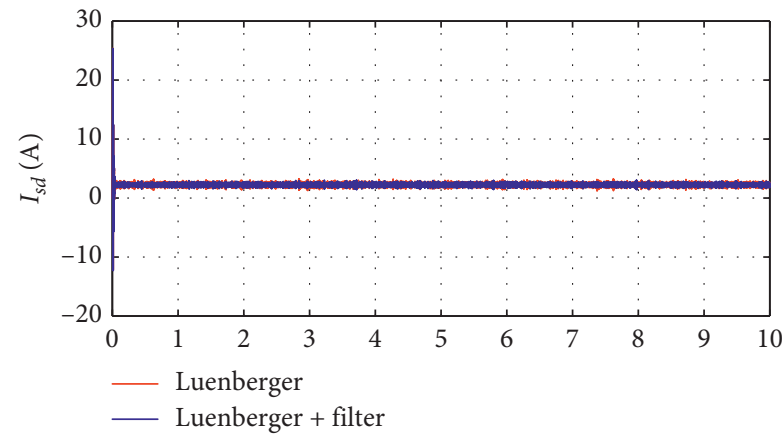

(c)

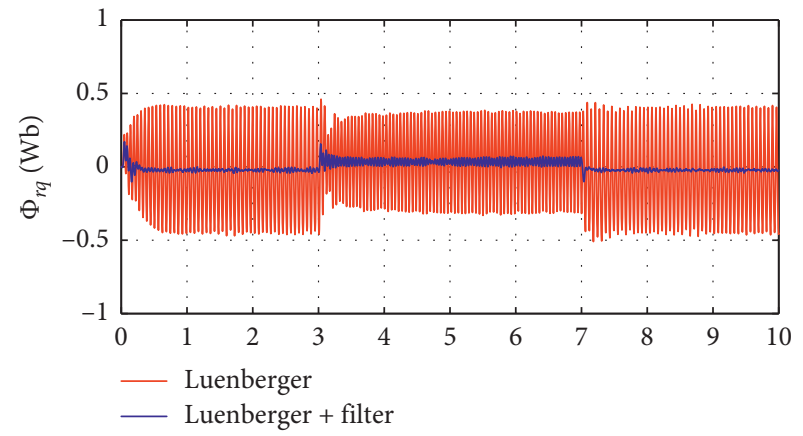

(b)

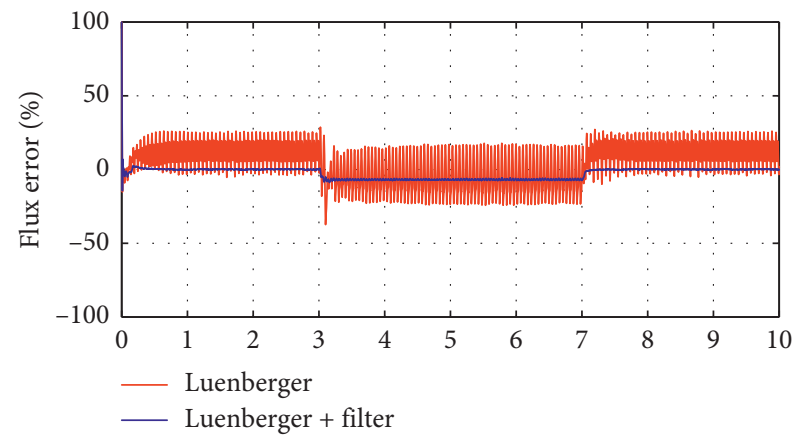

(d)

Figure 8: (a) $d$-axis rotor flux. (b) $q$-axis rotor flux. (c) $d$-axis stator current. (d) Flux error.

As known, the system control is sensitive to the load torque disturbance, the parametric variation, and noise measurements. All these parameters affect the system response.

Indeed, the stator resistance and the load torque affect especially the flux orientation, while the noise measurements disturb the speed and torque responses.
According to the simulations, the reduced-order observer designed is insensitive to the parametric variation and allows filtering the noise measurements, which reduces the total harmonic distortion (THD).

To not restrict the study to medium speed and to validate the proposed structure for a wide range of speeds, the 

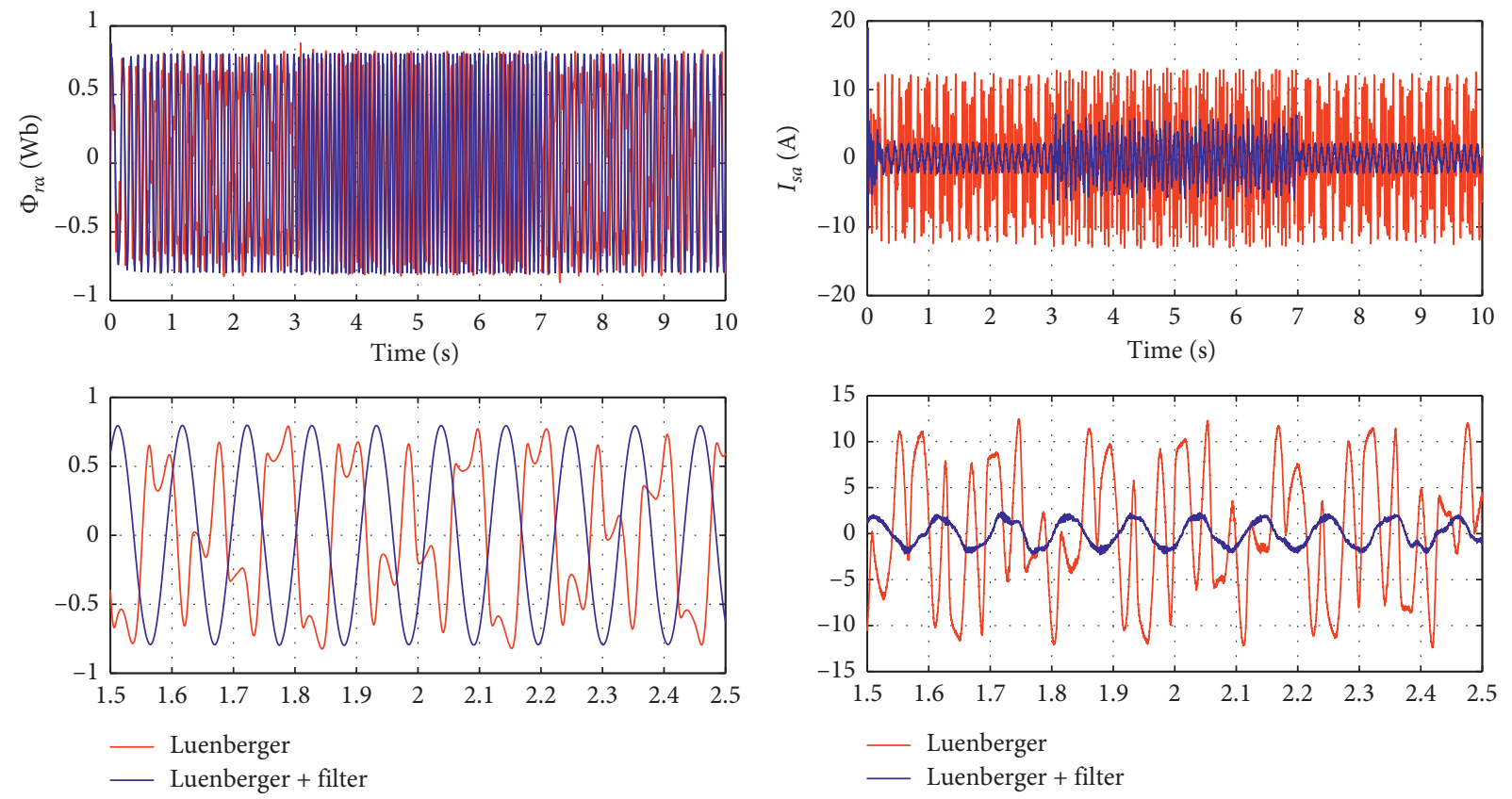

(a)

(b)

Figure 9: (a) $\alpha$-axis rotor flux. (b) Stator current.

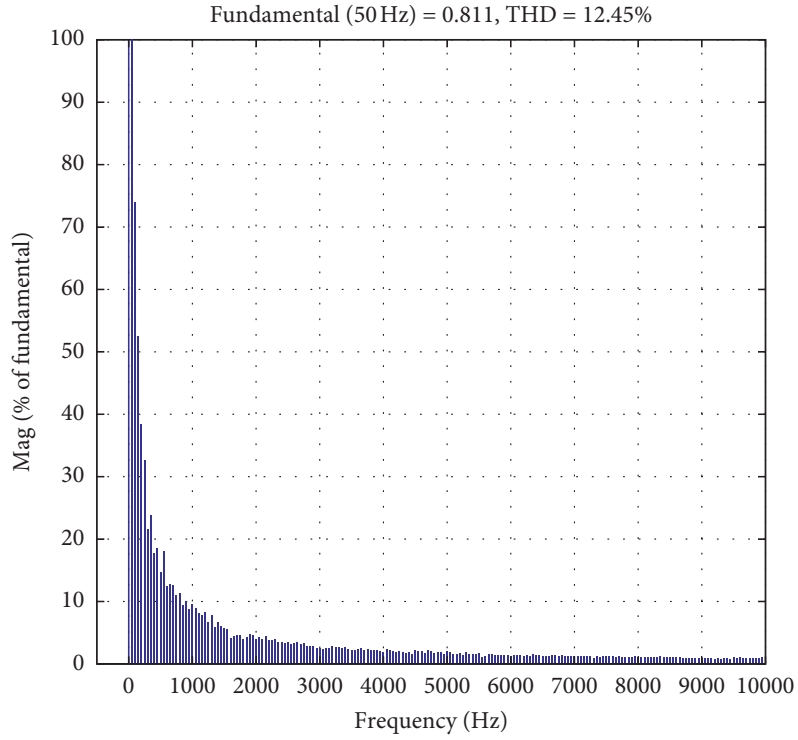

Figure 10: Spectrum analysis of stator current using only the full-order observer. 


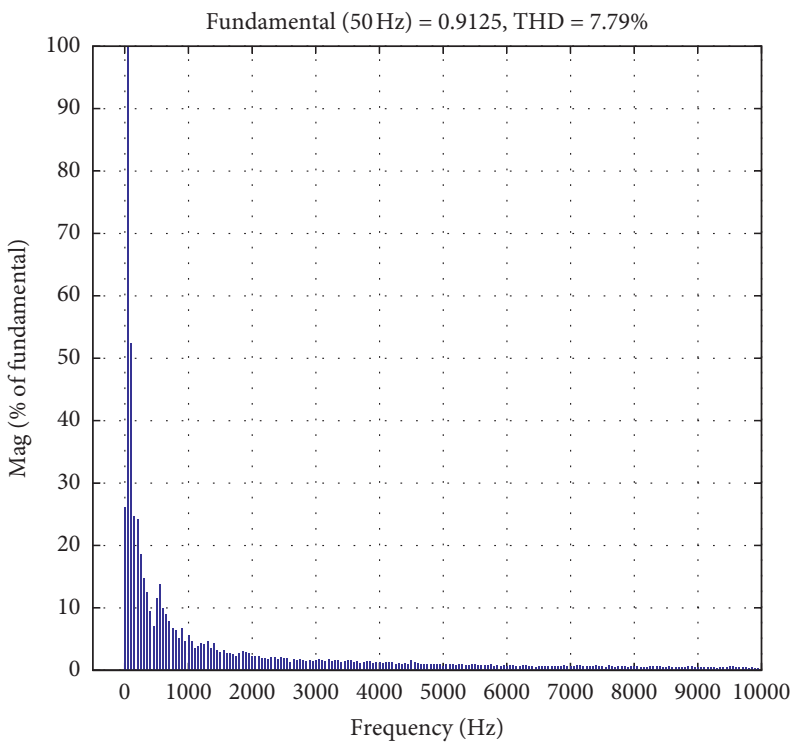

FiguRE 11: Spectrum analysis of stator current using the Luenberger and the reduced-order observer.

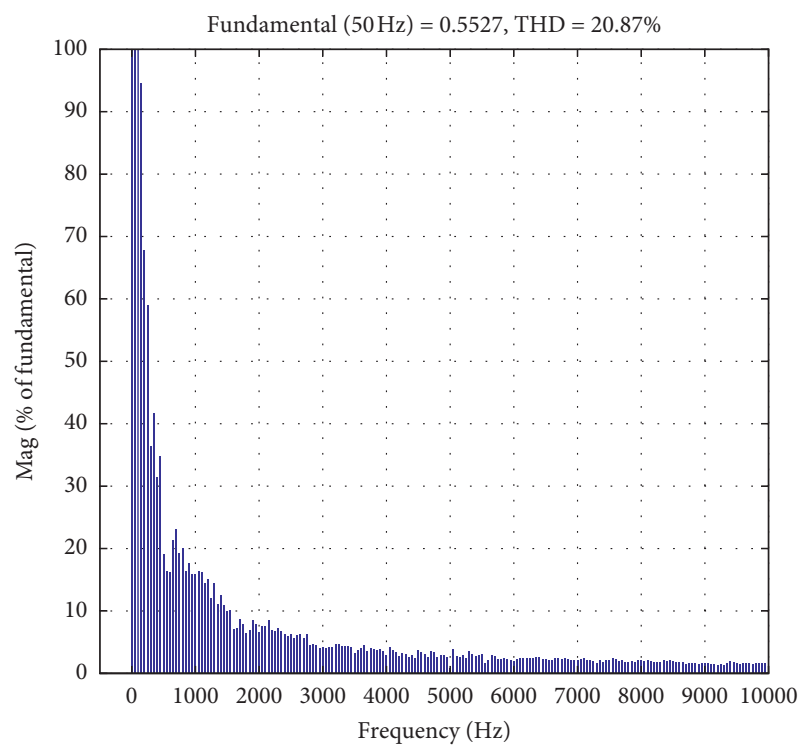

FIGURE 12: Spectrum analysis of electromagnetic torque using only the full-order observer.

following simulations show the obtained results at low speed.

As can be noticed in Figure 14(a), the estimated speed follows the reference when the filter is used, while with the Luenberger observer alone, ripples are very great. The same

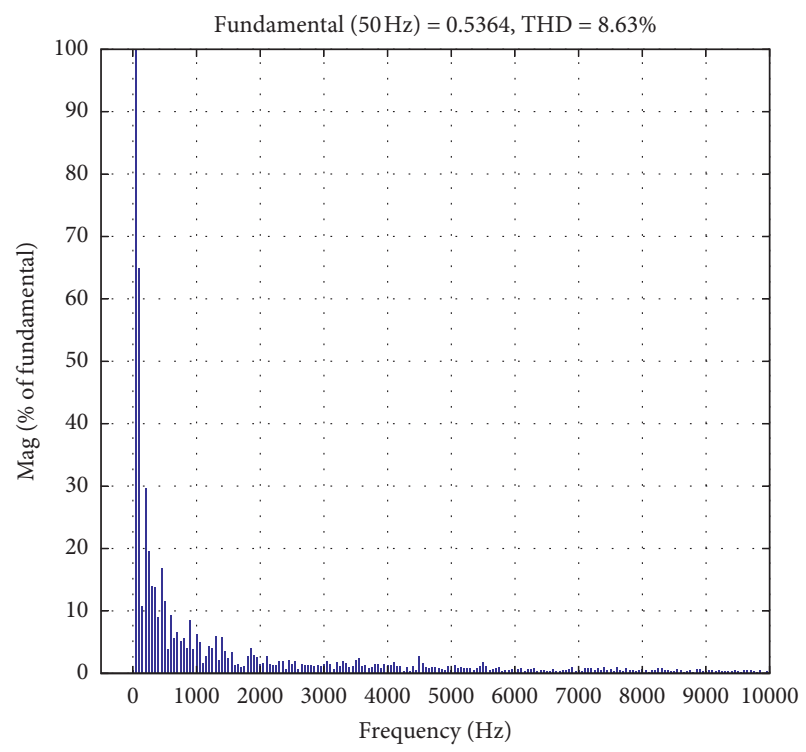

FIGURE 13: Spectrum analysis of electromagnetic torque using the Luenberger and the reduced-order observer.

effect is observed for the electromagnetic torque in Figure 14(b). Also, the flux orientation is no longer maintained (Figure 14(c)), and the flux error is bigger (Figure 14(d)). The disturbances appear for both $\alpha$-axis rotor flux and $d$-axis stator current in Figure 15. 


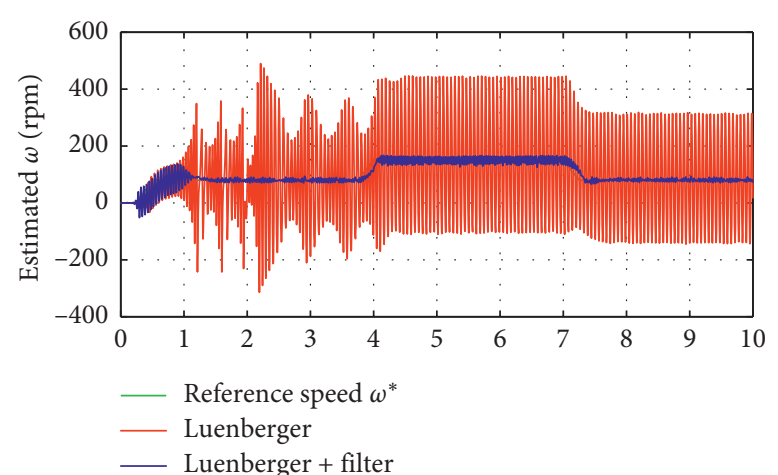

(a)

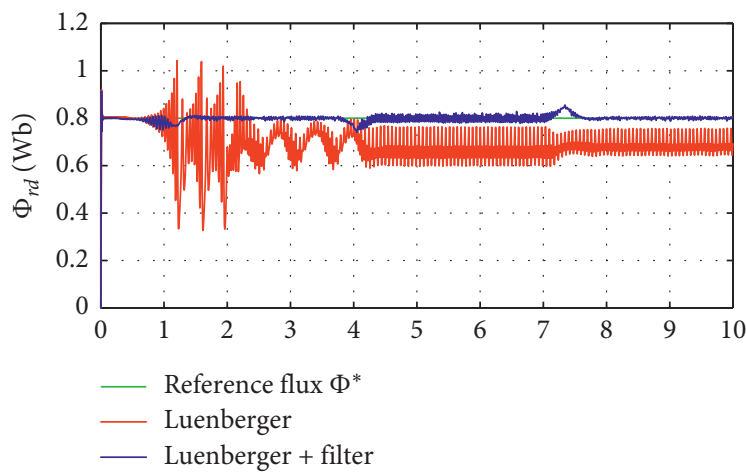

(c)

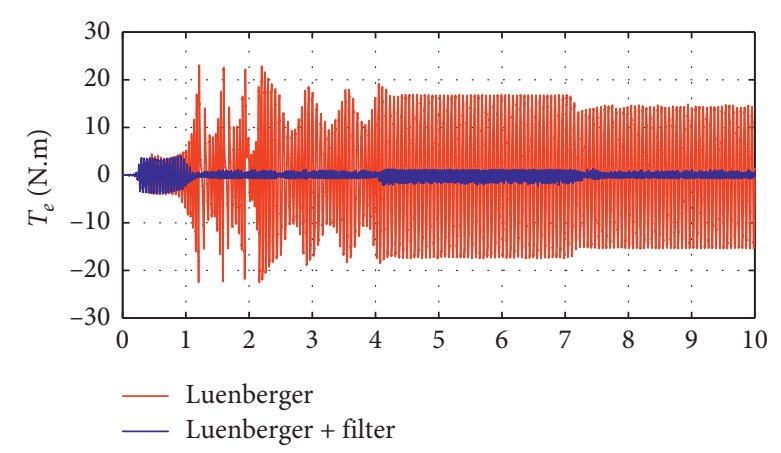

(b)

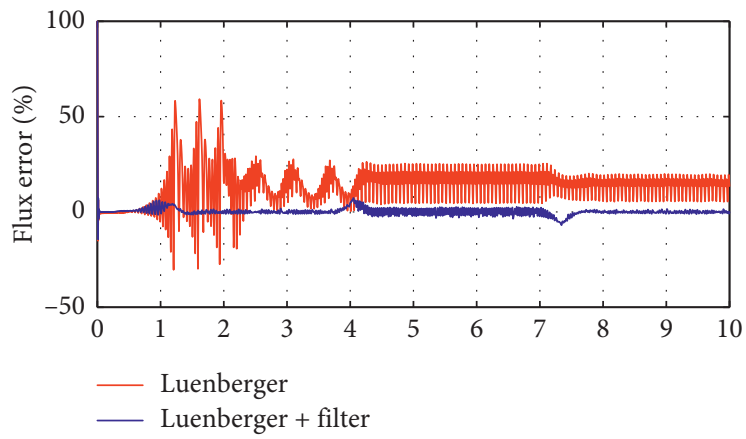

(d)

Figure 14: (a) Estimated speed. (b) Electromagnetic torque. (c) $d$-axis rotor flux. (d) Flux error.

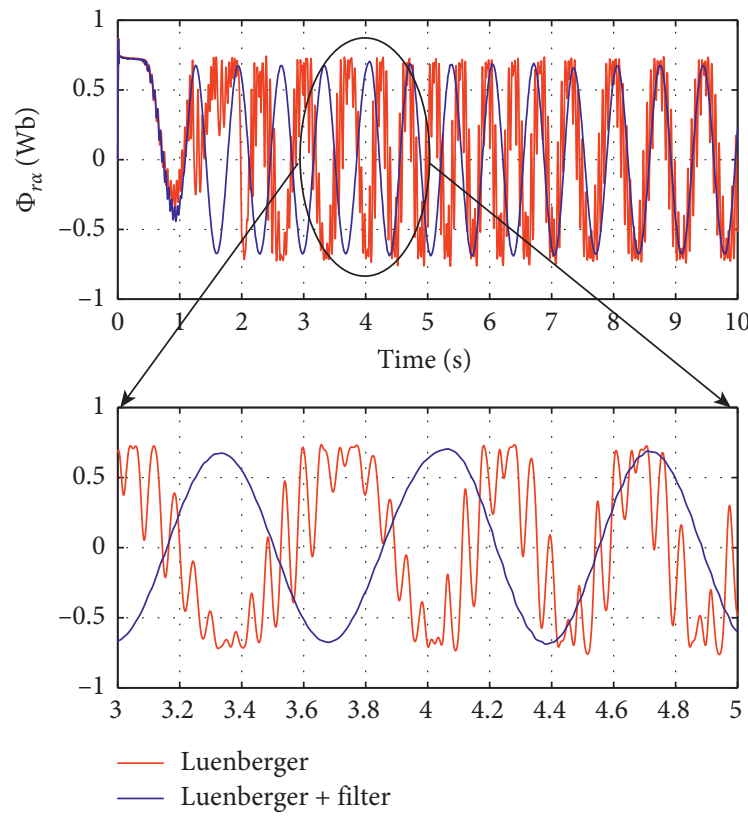

(a)

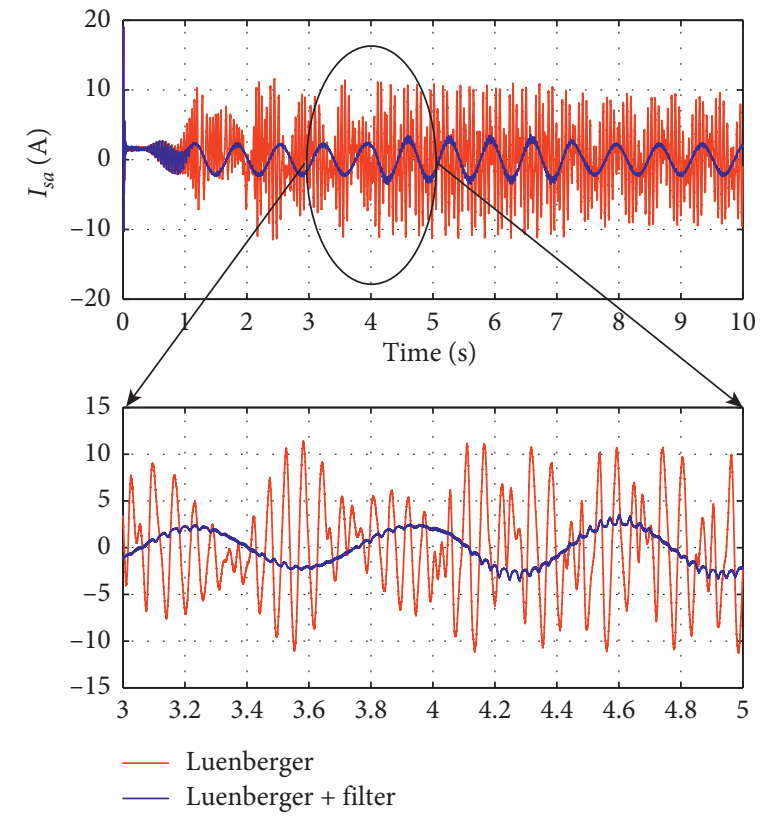

(b)

Figure 15: (a) $\alpha$-axis rotor flux. (b) Stator current.

\section{Conclusion}

The purpose of this study is to design a robust reduced-order observer insensitive to the parametric variation and noise measurements for IM drives. The control system involves a cascade structure that combines two observers. The fullorder adaptive Luenberger observer ensures the sensorless vector control of the induction motor. It allows the 
estimation of stator current and rotor flux used to design the rotor speed adaptive mechanism. The stability is proved by the Lyapunov criteria. This observer is more effective when the noise measurement is limited. To accurize the system response in the presence of this disturbances including the parametric variation, the flux reduced-order observer is inserted between the measured currents and the full-order observer. It allows the filtering of stator current. The estimated current technique is enhanced using a new technique to avoid the impact of the noise in the observer. The spectrum analysis of stator current and electromagnetic torque were presented using the Luenberger and the reduced-order observer. The actual structure is insensitive to noise measurements and parametric variation.

\section{Nomenclature}

$\begin{array}{ll}i_{s}, u_{s}: & \text { Stator current and voltage } \\ \Phi_{s}, \Phi_{r}: & \text { Stator and rotor flux } \\ \omega: & \text { Rotor speed } \\ v_{p}, v_{a, b, c}: & \text { Carrier and reference three-phase voltage } \\ V_{\mathrm{dc}}: & \text { DC bus voltage } \\ S_{1,2,3}, S_{1,2,3}^{\prime}: & \text { Switch states } \\ T_{e}, T_{l}: & \text { Electromagnetic torque and load torque } \\ X_{e}: & \text { Filter parameter } \\ \widehat{X}_{:}: & \text {Estimated parameter } \\ X^{*}: & \text { Reference } \\ s: & \text { Laplace variable } \\ \mathfrak{R}(X): & \text { Real part of } X \\ \mathfrak{I}(X): & \text { Imaginary part of } X .\end{array}$

\section{Data Availability}

There are no data to provide as part of the supplementary information to the article.

\section{Conflicts of Interest}

The authors declare that they have no conflicts of interest regarding the publication of this paper.

\section{References}

[1] M. Cirrincione, M. Pucci, and G. Vitale, Power Converters and AC Electrical Drives with Linear Neural Networks, CRC Press, Boca Raton, FL, USA, 2016.

[2] T. Ramesh, A. Kumar Panda, and S. Shiva Kumar, "Type-2 fuzzy logic control based MRAS speed estimator for speed sensorless direct torque and flux control of an induction motor drive," ISA Transactions, vol. 57, pp. 262-275, 2015.

[3] G. Ellis, "Control systems and the role of observers," in Observers in Control Systems, pp. 1-4, Academic Press, Cambridge, MA, USA, 2002.

[4] G. Ellis, "Control-system background," in Observers in Control Systems, pp. 5-39, Academic Press, Cambridge, MA, USA, 2002.

[5] G. Wang, G. Zhang, and D. Xu, Position Sensorless Control Techniques for Permanent Magnet Synchronous Machine Drives, Springer, Singapore, 2020.

[6] A. A. Z. Diab, A.-H. M. Al-Sayed, H. H. Abbas Mohammed, and Y. S. Mohammed, Development of Adaptive Speed
Observers for Induction Machine System Stabilization, Springer, Singapore, 2020.

[7] S. Yang, X. Li, Z. Xie, and X. Zhang, "A combined speed estimation scheme for indirect vector-controlled induction motors," Electrical Engineering, vol. 100, no. 4, pp. 2243-2252, 2018.

[8] L. S. Murugan and P. Maruthupandi, "Sensorless speed control of 6/4-pole switched reluctance motor with ANFIS and fuzzy-PID-based hybrid observer," Electrical Engineering, vol. 102, no. 2, pp. 831-844, 2020.

[9] Y. Mederharhet, O. Bennis, F. Benchabane, A. Titaouine, and A. Guettaf, "Characteristics of speed sensorless vector controlled induction motor with high efficiency taking core loss into account," Procedia Computer Science, vol. 83, pp. 824831, 2016.

[10] G. Ellis, "Noise in the luenberger observer," in Observers in Control Systems, pp. 141-172, Academic Press, Cambridge, MA, USA, 2002.

[11] K. Zeb, "Adaptive fuzzy logic controller for indirect field oriented controlled induction motor," in Proceedings of the 2019 2nd International Conference on Computing, Mathematics and Engineering Technologies (iCoMET), pp. 1-6, Sukkur, Pakistan, 2019.

[12] Z. Guo, J. Zhang, Z. Sun, and C. Zheng, "Indirect field oriented control of three-phase induction motor based on current-source inverter," Procedia Engineering, vol. 174, pp. 588-594, 2017.

[13] H.-S. Kim, H.-T. Moon, and M.-J. Youn, "On-line dead-time compensation method using disturbance observer," IEEE Transactions on Power Electronics, vol. 18, no. 6, pp. 13361345, 2003.

[14] R. Guedouani, B. Fiala, and M. S. Boucherit, "Implementation of multi-carrier PWM using a DSP TMS320F28335. Application to series multicellular single-phase inverter," in Proceedings of the 2017 10th International Conference on Electrical and Electronics Engineering (ELECO), Bursa, Turkey, December 2017.

[15] Y.-H. Liu and C.-L. Chen, "Novel dead time compensation method for induction motor drives using space vector modulation," IEE Proceedings-Electric Power Applications, vol. 145, no. 4, pp. 387-392, 1998.

[16] Z. Miao, J. Wei, T. Guo, and M. Zheng, "Dead-time compensation method based on field oriented control strategy," IOP Conference Series: Earth and Environmental Science, vol. 358, no. 4, pp. 0-8, 2019.

[17] H. Kubota, K. Matsuse, and T. Nakano, "DSP-based speed adaptive flux observer of induction motor," IEEE Transactions on Industry Applications, vol. 29, no. 2, pp. 344-348, 1993.

[18] K. Åström and B. Wittenmark, Computer Controlled Systems Theory and Design, Prentice-Hall, Upper Saddle River, NJ, USA, 1997.

[19] G. Ellis, "Using the luenberger observer in motion control," in Control System Design Guide, pp. 407-429, ButterworthHeinemann, Oxford, UK, 4th edition, 2012.

[20] D. Xu, B. Wang, G. Zhang, G. Wang, and Y. Yu, "A review of sensorless control methods for AC motor drives," CES Transactions on Electrical Machines and Systems, vol. 2, no. 1, pp. 104-115, 2019.

[21] B. Peterson, Induction Machine Speed Estimation-Observations on Observers, Lund Institute of Technology-Sweden, Lund, Sweden, 1996. 